\title{
Tabela periódica e o corpo humano uma sequência didática para o ensino de
}

\section{Química}

\author{
Periodic table and the human body a didactic sequence for teaching Chemistry
}

\section{La tabla periódica y el cuerpo humano una secuencia didáctica para la enseñanza de la Química}

\section{Resumo}

O presente trabalho tem como objetivo o desenvolvimento e a aplicação de uma sequência didática elaborada com base nos três momentos pedagógicos. Para isso ela foi desenvolvida para turmas do primeiro ano do ensino médio, tendo como tema "A Tabela Periódica e o Corpo Humano", no primeiro momento pedagógico foi levado aos alunos uma situação problema envolvendo o tema, e questões para levantamento do conhecimento prévio. Logo em seguida no segundo momento pedagógico de aporte do quadro, vídeo, textos de apoio e questões, foi levantado o conteúdo de tabela periódica, sempre fazendo um link ao tema gerador. Por fim no último momento pedagógico foi utilizado um jogo similar ao super trunfo, O jogo chamado: Xenubi, trazia aspectos relacionados as propriedades periódicas em suas cartas. E também nesse último momento foi utilizado de embalagens alimentícias para que os alunos responderem as questões de extrapolação. A sequência didática mostrou-se uma importante ferramenta de ensino, pois seguindo as análises dos resultados os estudantes tiveram ao final uma aprendizagem efetiva, também essa ferramenta de ensino promove o debate dentro da sala de aula, fazendo com isso os alunos se tornem cidadãos mais críticos e atuantes no mundo em que vivem.

Palavras-chave: Tabela periódica; Corpo Humano; Três momentos pedagógicos.

\begin{abstract}
The present work aims to develop and apply a didactic sequence based on the three pedagogical moments. For this, it was developed for first-year high school classes, with the theme "The Periodic Table and the Human Body", in the first pedagogical moment, a problem situation involving the subject was taken to the students, as well as questions for surveying prior knowledge. Right after, in the second pedagogical moment of contribution of the board, video, support texts and questions, the content of the periodic table was raised, always linking to the generating theme. Finally, at the last pedagogical moment, a game similar to the super trump was used, The game called: Xenubi, had aspects related to the periodic properties in its cards. And also at this last moment, food packaging was used for students to answer extrapolation questions. The didactic sequence proved to be an important teaching tool, because following the analysis of the results, the students had an effective learning in the end. This teaching tool also promotes debate within the classroom, making students become more citizens. critics and actors in the world in which they live. Keywords: Periodic table; Human body; Three pedagogical moments.
\end{abstract}




\begin{abstract}
Resumen
El presente trabajo tiene como objetivo desarrollar y aplicar una secuencia didáctica a partir de los tres momentos pedagógicos. Para ello, se desarrolló para las clases de primer año de bachillerato, con el tema "La Tabla Periódica y el Cuerpo Humano", en el primer momento pedagógico se llevó a los estudiantes una situación problemática que involucraba la asignatura, así como preguntas para relevamiento de conocimientos previos. Inmediatamente después, en el segundo momento pedagógico de aportación de la pizarra, video, textos de apoyo y preguntas, se planteó el contenido de la tabla periódica, siempre vinculando al tema generador. Finalmente, en el último momento pedagógico, se utilizó un juego similar al super trump, El juego llamado: Xenubi, tenía aspectos relacionados con las propiedades periódicas en sus cartas. Y también en este último momento, se utilizó el empaque de alimentos para que los estudiantes respondieran preguntas de extrapolación. La secuencia didáctica resultó ser una herramienta didáctica importante, ya que luego del análisis de los resultados, los estudiantes tuvieron un aprendizaje efectivo al final. Esta herramienta didáctica también promueve el debate dentro del aula, haciendo que los estudiantes se conviertan en más ciudadanos, críticos y activos en la mundo en el que viven.
\end{abstract}

Palabras clave: Tabla periodica; Cuerpo humano; Tres momentos pedagógicos.

\title{
1. Introdução
}

Um dos grandes desafios enfrentados pelas as universidades que tem dentro dos seus cursos a licenciatura, está na formação de educadores para o nível de educação básica, ou seja, na formação de professores que irão atuar no ensino público ou privado formativo, colaborando de maneira positiva para que os jovens cidadãos exerçam conscientemente sua cidadania e sejam mais atuantes na sociedade (Santos, Gauche, de Souza Mól, da Silva, \& de Aguiar Baptista, 2006).

O objetivo dos cursos de Licenciatura em Química é formar o professor para atuar na educação básica. Tal formação deve contemplar inúmeros aspectos inerentes à formação do bom professor, tais como conhecimento do conteúdo a ser ensinado, conhecimento curricular, conhecimento pedagógico sobre a disciplina escolar Química, conhecimentos sobre a construção do conhecimento científico, especificidades sobre o ensino e a aprendizagem da ciência Química, entre outros (Silva \& Oliveira, 2009).

O Ensino Médio é caracterizado por ser um nível de ensino repleto de peculiaridades, de ordem cronológica e sociocultural, como a presença de alunos adolescentes, jovens e adultos, com trajetórias e condições de vida complexas e diferenciadas, que relevam diversidades culturais, sociais, econômicas, étnico-raciais, de gênero, entre outras, que influenciam as relações e processo de escolarização (Silva, \& Coffani, 2013).

$\mathrm{O}$ conceito de adquirir novos conhecimentos, além de novas informações podem ser aprendidas e mantidas, à medida que existam uma estrutura cognitiva do ensino. Em outras palavras, a interação não é com qualquer conhecimento prévio, dessa forma, compreender um dado requer utilizar conceitos, ou seja, relacioná-los dentro de uma rede de significados que explique por que ocorrem e que consequências eles têm. Infere-se que compreender é ativar uma ideia ou um conhecimento para uma mudança conceitual (Nunes, 2017).

Um dos maiores desafios do Ensino de Química atual é proporcionar aos estudantes a compreensão dos princípios do pensamento químico, superando uma prática pedagógica que se atém a simples memorização mecânica de alguns conteúdos isolados de Química. A Tabela Periódica (TP) é um instrumento utilizado na consulta e previsão de um grande número de propriedades químicas dos elementos. É chamada de periódica porque mostra a repetição de algumas propriedades que determinados elementos têm em comum. No entanto, pesquisas relatam que ela vem sendo utilizada por estudantes do Ensino Médio apenas como fonte de consulta de dados e informações numéricas, ficando esquecida sua questão central, que é a periodicidade dos elementos químicos (Godoy \& Mesquita, 2012; Medeiros, 2013; Trassi, Castellani, Gonçalves, \& Toledo, 2001, Wartha, Silva, \& Bejarano, 2013).

Em oposição ao que tem-se praticado no âmbito escolar, Delizoicov (2001), relata que a sala de aula seja um espaço que propicie a mediação do professor, possibilite o diálogo e permita o conhecimento sob novas ópticas de compreensão que supere o senso comum. O professor deve buscar propostas de ensino que relacionem os conhecimentos científicos com a 
realidade escolar e suas peculiaridades, possibilitando ao aluno a condições de agir como cidadão, argumentando suas ações, decisões e criticidade (Silva, 2011).

Desta maneira, contextualizar a química não é interligar meramente o conhecimento e cotidiano, nem citar exemplos com ilustrações ao final de determinados conteúdos, mas é propor "situações problemáticas reais e buscar o conhecimento necessário para entendê-las e solucioná-las" (Brasil, 1999, De Almeida et al., 2008).

O presente trabalho tem como objetivo propor uma sequência didática estruturadas nos três momentos pedagógicos, a fim de contextualizar o ensino de química, buscando assim estimular o interesse do estudante pelo conteúdo e formar um cidadão mais reflexivo.

\section{Metodologia}

O presente estudo trata-se de um artigo de pesquisa (Pereira, Shitsuka, Pereira, \& Shitsuka, 2018). A presente proposta foi desenvolvida de uma sequência de ensino embasada nos três momentos pedagógicos propostos por Delizoicov (2001).

A sequência didática foi executada em três primeiros anos do ensino médio do Colégio Estadual Polivalente de Apucarana, com turmas numerosas, cada turma tinha inicialmente cerca de 35 alunos, a turma era composta por sua maioria de alunos de classe média baixa, tinham acesso a internet, também gostavam de assistir séries.

Foram realizadas quatro aulas de 50 minutos cada em cada turma. O conteúdo foi selecionado em conversa com a professora regente da turma, em que cedeu o tema de Tabela periódica.

\subsection{Apresentação das etapas da sequência}

A utilização dos três momentos pedagógicos proposto por Delizoicov (2001) permite que utiliza-se temas geradores como fonte de problemas, isso faz com que desperte ao estudante a necessidade de aprender novos conceitos, assim ampliando e tendo uma aprendizagem mais eficaz (Marengão, 2012).

Este método de ensino é composto por três momentos: Problematização Inicial, Organização do Conhecimento e Aplicação do Conhecimento sendo cada um explicado abaixo.

No primeiro momento, a problematização inicial, são propostos aos alunos situações corriqueiras ou fictícias, esses problemas estão relacionados ao tema escolhido, para que assim o aluno levante hipóteses e crie uma discussão sobre o tema, para que assim os estudantes tenham um maior interesse pelo tema, e por conseguinte pelo conteúdo (Lyra, 2013).

Essa etapa é uma etapa onde o estudante será o centro da aprendizagem, o professor somente irá mediar as discussões.

Com isso fizemos a escolha do tema a será trabalhado "A Tabela Periódica e o Corpo Humano". A partir disso e com a análise do perfil da turma, ficou evidenciados que alguns alunos traziam uma animação que assistiam com frequência, Rick and Morty, uma animação da netflix.

Partindo disso encontramos um episódio no qual Morty entra dentro do corpo humano e propomos o seguinte problema:

"Visualmente somos diferentes, no que diz respeito a nossa estrutura física, cor dos olhos, altura, cor do cabelo, porém, internamente somos todos iguais. Imagine que você é o Morty, da animação Rick and Morty, e entra no corpo humano através de nave tecnológica, o que você espera encontrar? E o que nos torna internamente iguais?"

Junto a essa questão problema foi entregue aos alunos as seguintes questões para levantar o conhecimento prévio deles:

"O que você sabe sobre tabela periódica?"

"O que você acha que significa o termo periódico?"

"Como a tabela periódica é dividida? Isso te lembra à alguma situação do seu cotidiano?" 
Com isso finalizou-se o primeiro momento pedagógico.

No segundo momentos pedagógico, a organização do conhecimento, os conteúdos são abordados para solucionar os problemas levantados na etapa anterior (Marengão, 2012). Delizoicov (2001) e Angotti (1991) destacam que este é o momento de estudar os conhecimentos fundamentais para que o tema central e a problematização inicial possam ser compreendidos, sob a orientação do professor.

Dando sequência a aula, realizou a leitura de um texto sobre "os elementos no corpo humano" (Levorato et al., 2007), nesse texto ele trazia do que o corpo humano é constituído internamente, levando o aluno a relacionar aos elementos químicos, a leitura do texto for realizada com os alunos de forma que os alunos fossem lendo e do professor para o mesmo auxílio no entendimento do texto por parte dos alunos.

Posteriormente foi passado um vídeo sobre a história da tabela periódica, desde os primórdios até a tabela periódica conhecida hoje em dia, esse vídeo está disponível no youtube (Help Quimica, 2018).

Na próxima aula foi realizado a leitura de um novo texto, "os principais elementos químicos encontrados no corpo humano' (Levorato et al., 2007), nesse texto o autor aborda os principais elementos químicos encontrados no corpo humano e suas respectivas porcentagens e suas funções dentro do organismo, a leitura desse texto seguiu a mesma dinâmica da leitura anterior.

Com isso no quadro foi abordado de forma dialogada os períodos, as famílias dos elementos, e também suas respectivas classes e suas características.

Logo em seguida foi entregue aos alunos mais duas questões para ir organizando o conhecimento dos alunos:

"Classifique os elementos do texto anterior em metais e ametais."

"Localize-os dentro da tabela periódica, suas respectivas famílias e períodos."

Essas questões os alunos foram respondendo de forma individual com o intermédio do professor.

$\mathrm{Na}$ terceira aula foi retomado o conteúdo visto na aula anterior, e no quadro de forma dialogada foi explicado para os alunos as principais propriedades periódicas que são: Eletropositividade, Eletronegatividade, Energia de Ionização e Raio atômico.

Com isso termina o segundo momento pedagógico.

O terceiro momento pedagógico, a aplicação do conhecimento, nesse momento o estudo utiliza os seus novos conhecimentos adquiridos para extrapolar o seu conhecimento, ou seja o estudante após assimilar o conteúdo e o tema trabalhado, aplica o mesmo conteúdo associado a outros temas (Lyra, 2013).

O Terceiro momento pedagógico iniciou no final da terceira aula, onde foi explicado aos estudantes as regras do jogo Xenubi, que eles iriam jogar, as regras são as seguintes:

Os alunos foram divididos em 4 grupos, e cada grupo foi novamente dividido em 2, para que assim existisse dentro do mesmo grupo jogadores e oponentes.

Cada grupo recebeu dois baralhos de 48 cartas cada, sendo um baralho do grupo jogador e outro do grupo oponente.

Cada carta tinha o elemento químico os valores das propriedades periódicas, e onde eles estavam localizados dentro da tabela periódica. Com isso o jogo permite ao aluno exercitar seu conhecimento quanto a relação das propriedades de um elemento químico e sua posição na tabela periódica.

O jogador deve analisar a posição dos elementos e escolher qual propriedade química do seu elemento é superior ao elemento do oponente

Durante o jogo os grupos vão fazendo um rodízio, o grupo que foi o jogador na primeira rodada, na segunda vira oponente a assim por diante. 
Quando o aluno acerta a resposta, ele ganha uma das cartas do oponente. Quando erra, perde uma carta para o oponente, ganha o jogo quem tiver o maior número de cartas.

Em seguida na última aula da sequência os alunos os alunos jogaram o jogo por 30 minutos.

E nessa mesma aula, foi entregue aos estudantes rótulos de alimentos para ser realizado as questões de extrapolação que eram as seguintes:

"Faça a classificação dos elementos químicos contidos nos rótulos alimentares."

"Monte um escala crescente de raio atômico desses elementos"

Por fim após a sequência terminar, os dados foram coletados de forma individual. Após os dados serem coletados, eles foram categorizados para uma melhor discussão dos resultados, esses dados foram categorizados com as respostas dos estudantes, o que era mais comum de aparecer ao longo das respostas, ou em categorias mais abrangentes como incorreta ou correta.

\section{Resultados e Discussão}

O início das aulas se deu com a apresentação de uma problematização inicial para os alunos.

Com isso os alunos foram respondendo o que eles esperariam ver dentro do corpo humano e o professor promovia uma discussão envolvendo o que havia sido respondido, no caso dos elementos químicos ficou a cargo do professor guiar os alunos a tal resposta.

A Figura 1 apresenta algumas das respostas que mais se repetiram entre os três primeiros anos, alguns alunos escolheram mais do que uma resposta, em que é possível evidenciar que os alunos concordam que sangue, órgãos, células, bactérias e ossos seriam encontradas no corpo humano.

Figura 1. Respostas referentes à problematização.

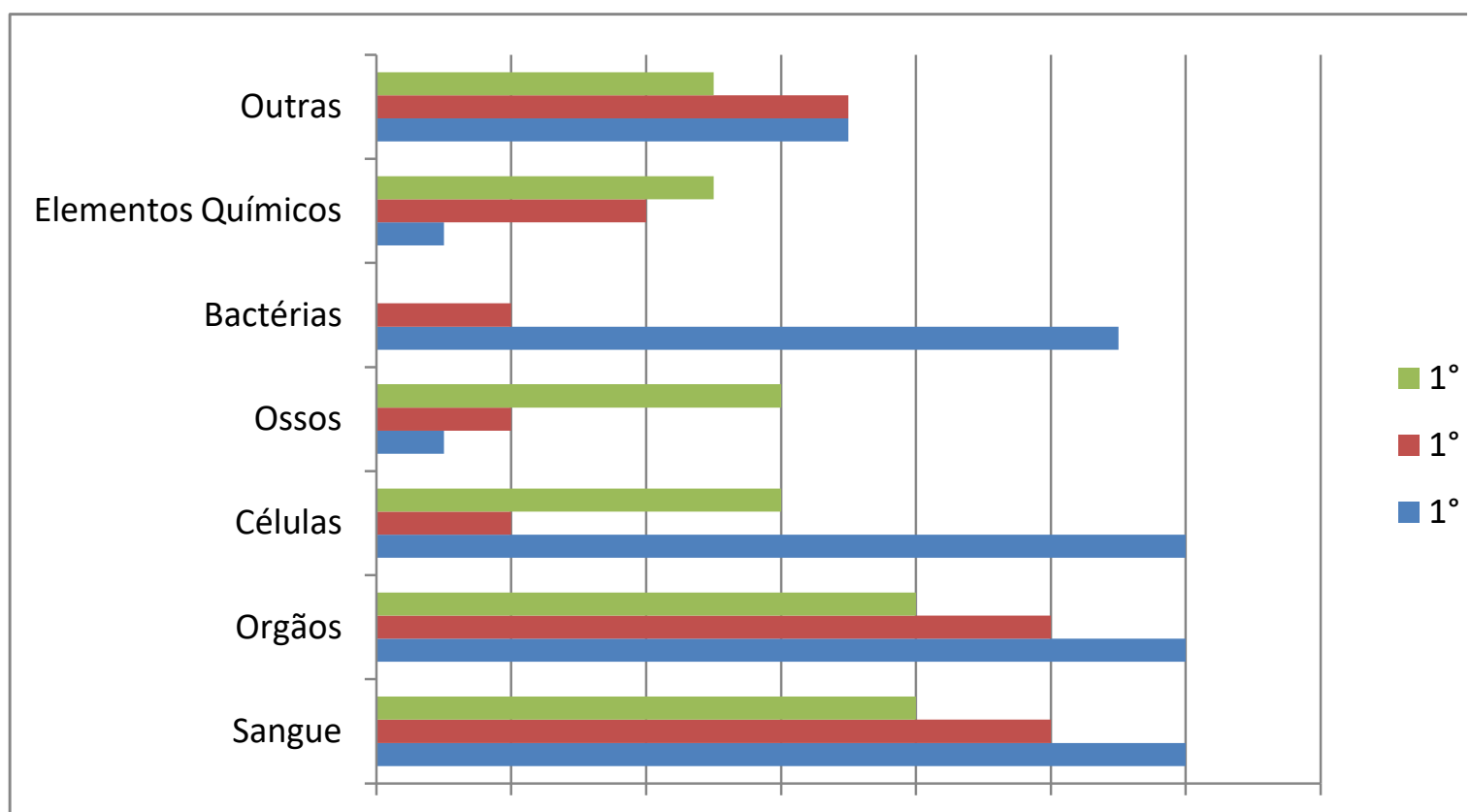

Fonte: Autores (2021). 
A categoria "Outras" apresenta respostas que pouco se repetiram, como veias, DNA, tecidos e musculo, que são encontradas no corpo humano, entretanto foram pouco apresentadas pelos grupos, tanto na folha de respostas como na discussão com o professor na sala de aula.

As respostas obtidas com os alunos foram satisfatórias, pois todos possuíam conhecimento de como o corpo humano era formado, da anatomia humana. As respostas "elementos químicos” eram as buscadas para dar início a sequência e diante das respostas de alguns grupos foi possível iniciar a discussão referente à tabela periódica com os alunos.

Em seguida foi apresentado aos alunos um questionário a fim de realizar o levantamento dos conhecimentos prévios dos alunos sobre o conteúdo de tabela periódica. O questionário consistia de três perguntas e foram respondidas pelos mesmos grupos da problematização.

A forma de apresentação das respostas dadas pelos alunos segue o padrão apresentado na problematização, em que respostas que mais se repetiram estão em destaque e as citadas em menor número estão agrupadas na categoria "Outras" e comentadas posteriormente. A primeira questão utilizada no questionário foi: O que você sabe sobre tabela periódica? E as respostas estão apresentadas na Figura 2.

Figura 2. Respostas referentes a questão 1 - O que você sabe sobre tabela periódica?

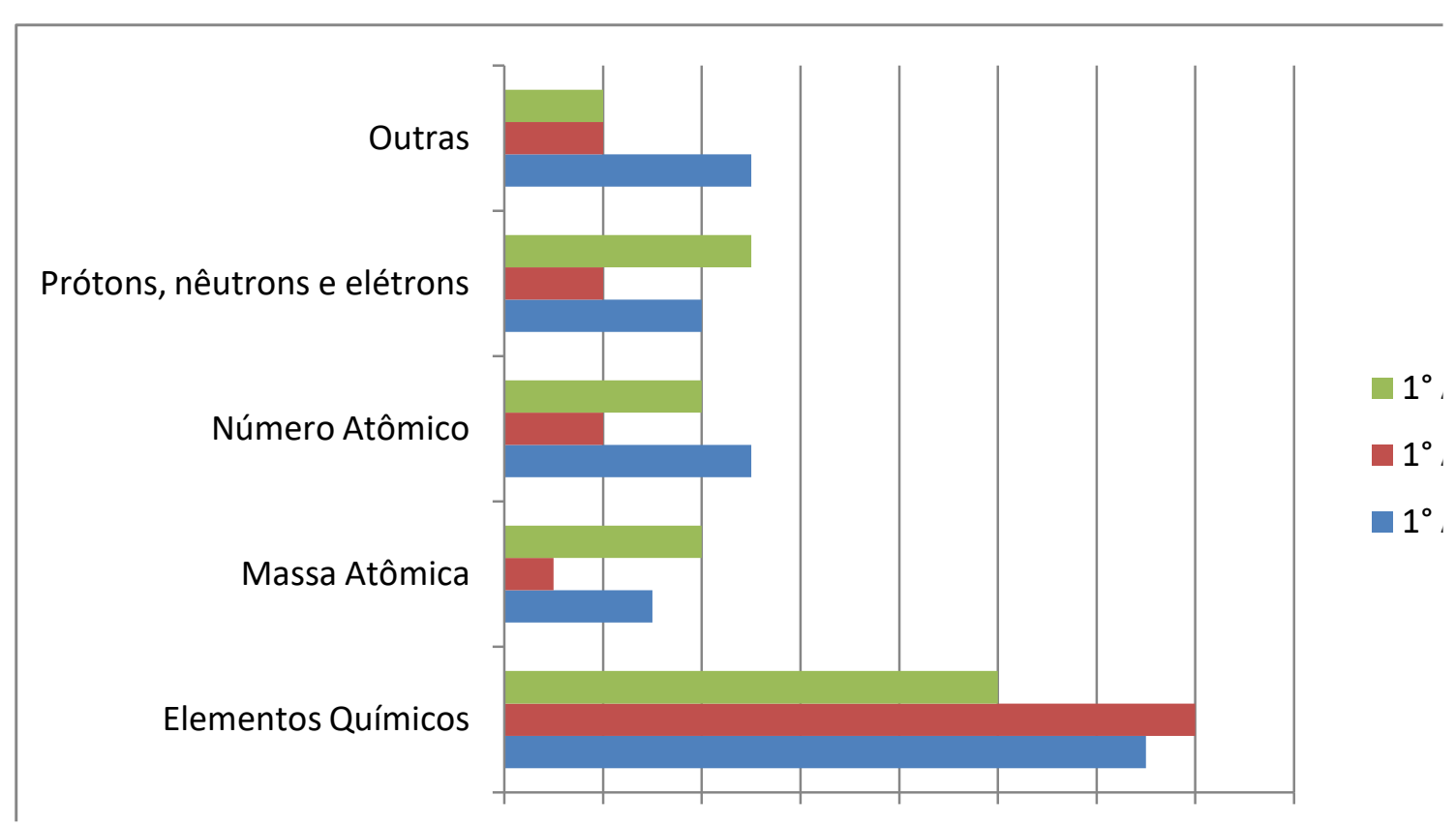

Fonte: Autores (2021).

A grande maioria dos estudantes imediatamente relaciona a tabela periódica com os elementos químicos e outras informações também são apresentadas como à massa e número atômico dos elementos e algumas respostas apresentadas, que não constam no gráfico, foram referentes às letras (símbolos) que estão dispostos na tabela, sobre a organização em famílias e períodos.

Os estudantes demonstraram possuir algum conhecimento sobre as informações que são possíveis obter com uma tabela periódica, visto que ainda era um conteúdo novo para os alunos.

A segunda questão utilizada no questionário foi: O que você acha que significa o termo periódico? A Figura 3 apresenta as respostas dos alunos. 
Figura 3. Respostas referentes à questão 2 - O que você acha que significa o termo periódico?

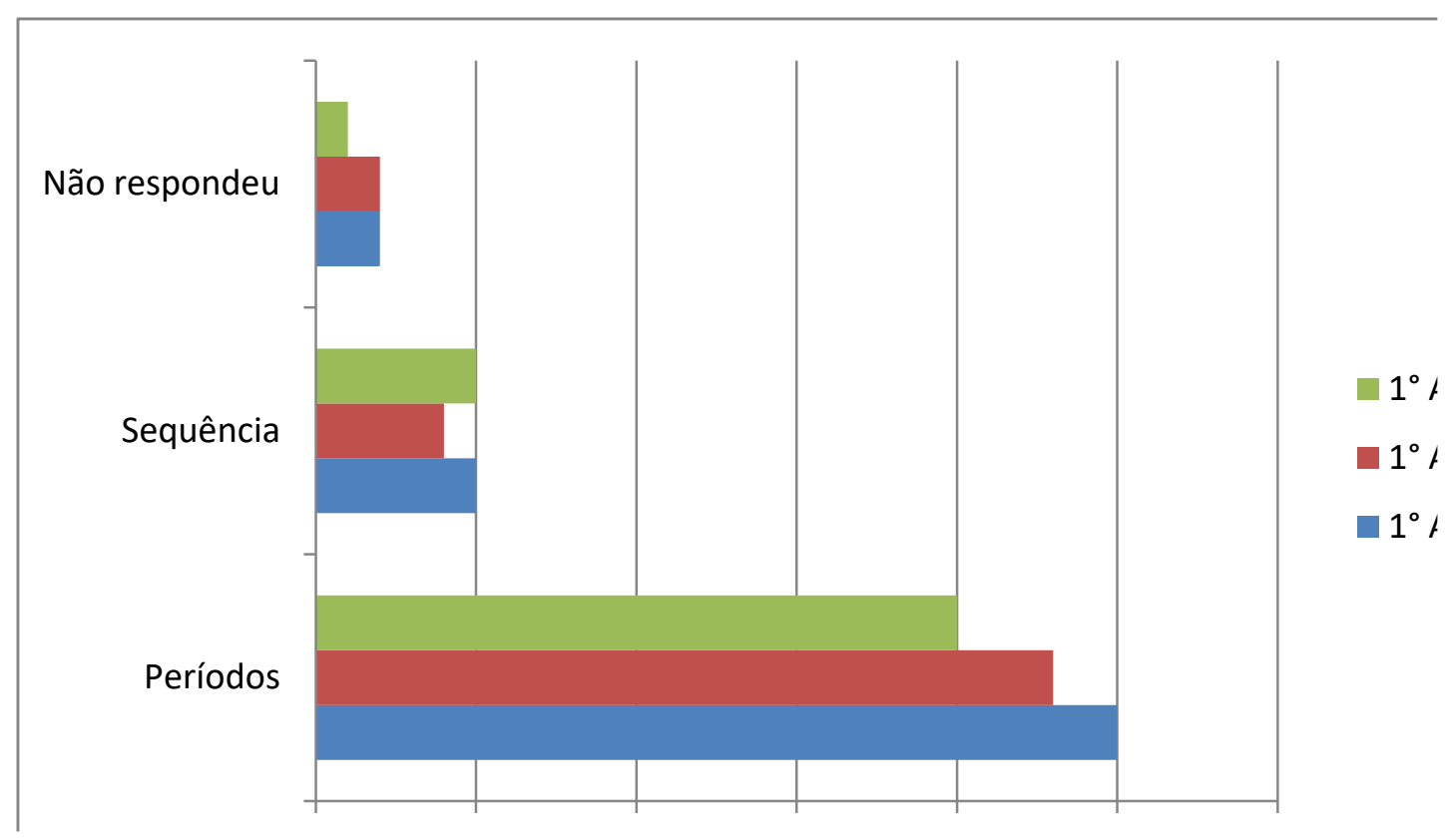

Fonte: Autores (2021).

Como pode ser observado, os alunos associam o termo periódico com períodos, algo que se repete ao longo de determinado termo, ou até mesmo uma sequência que possui algo em comum. Alguns alunos desconheciam a palavra e por isso optaram por não responder a pergunta, entretanto foi possível observar que nas discussões em grupos não houve um consenso do viria a ser o significado da palavra. Posteriormente o professor guiou os alunos a uma resposta para a pergunta.

Algo que pode ser destacado como positivo em virtude de ser possível utilizar este conhecimento demonstrado pelos mesmos para futuramente na sequência relacionar esse termo com as propriedades periódicas apresentadas na tabela, como eletronegatividade e raio atômico.

A última questão utilizada para realizar o levantamento do conhecimento prévio dos estudantes foi: Como a tabela periódica é dividida? Isso te lembra de alguma situação do cotidiano? A Figura 4 traz as respostas escritas e discutidas pelos alunos. 
Figura 4. Respostas referentes à questão 3 - Como a tabela periódica é dividida? Isso te lembra de alguma situação do cotidiano?

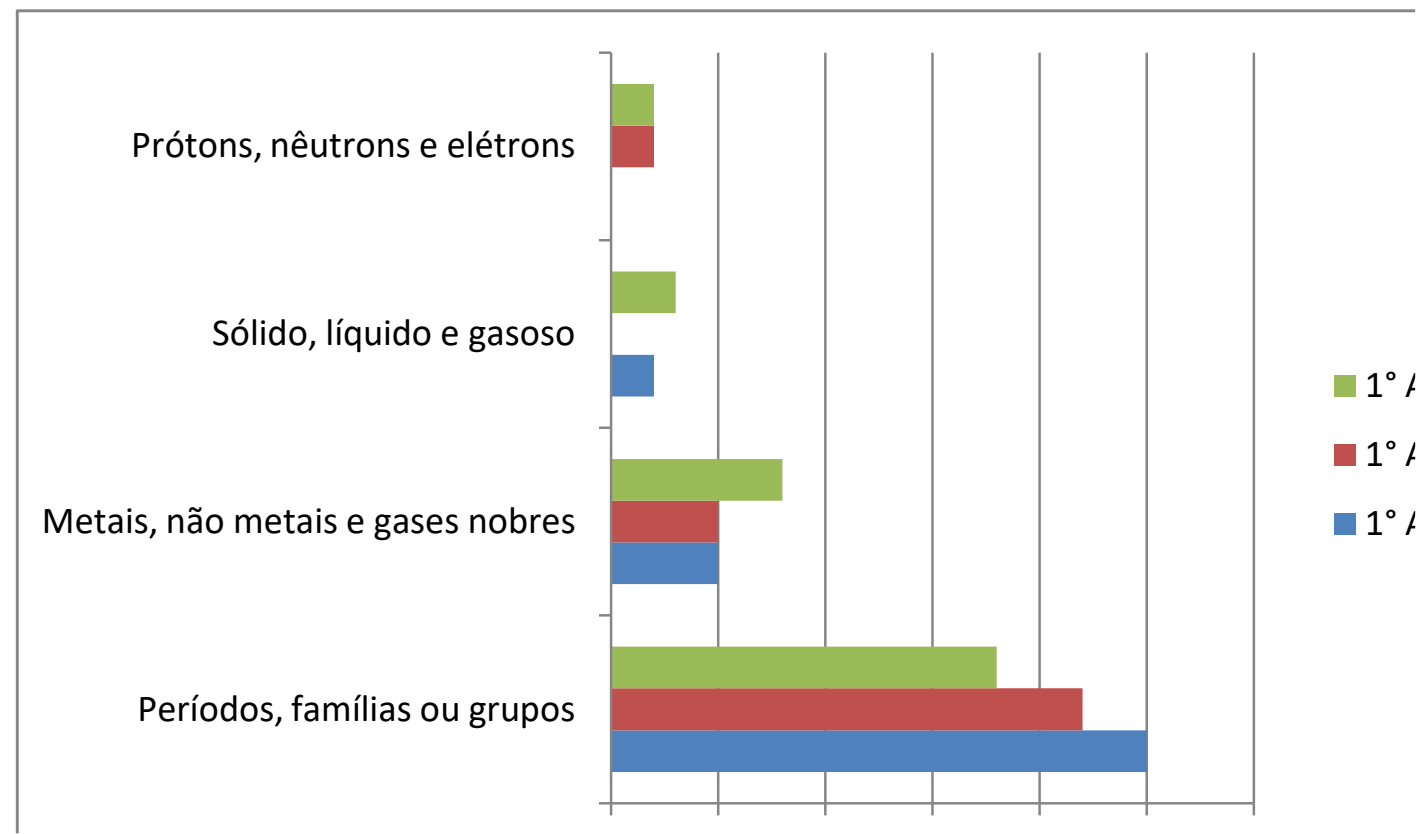

Fonte: Autores (2021).

A grande maioria dos estudantes reconhece a divisão da tabela periódica por períodos e famílias, entretanto alguns destacaram outras formas de divisão como metais, não metais e gases nobres.

O fato dos alunos citarem os estados e tipos de elementos encontrados na tabela evidencia que os mesmo já tiveram contato com a mesma e compreenderam as legendadas apresentas pelas tabelas periódicas apresentadas pelos livros didáticos.

Logo em seguida iniciou-se a etapa de organização do conhecimento nessa etapa os alunos responderam duas questões, ambas buscando verificar se os alunos conseguiram associar e identificar os elementos da tabela periódica com a sua organização e disposição na mesma.

A primeira questão: Classifique os elementos do texto anterior em metais, não metais e gases nobres? É pedido que os alunos classificassem os elementos apresentados no texto "Os principais elementos químicos encontrados no corpo humano", sendo eles o carbono, hidrogênio, oxigênio, nitrogênio, cálcio, potássio, fósforo.

Foram criadas 5 categorias para classificar as respostas apresentadas pelos alunos, sendo elas Correta, Incompleta, Apresenta erros, Não respondeu e Outro.

A resposta era classificada como "correta" caso não apresentasse erros em nenhum dos elementos propostos, a categoria "incompleta" abrangia respostas que faltaram algo referente a um ou mais elementos, a categoria "apresenta erros" viria ser respostas cujos elementos apresentassem algum erro de classificação. A classificação "outro" representava as respostas que não condiziam em nada com a pergunta e última classificação, "não respondeu", seria para perguntas deixadas em branco pelos estudantes.

A Figura 5 exibe o número de respostas dentro de cada categoria para a questão 1 e posteriormente é apresentado algumas respostas dos alunos. 
Figura 5. Respostas referentes à questão 1 - Classifique os elementos do texto anterior em metais, não metais e gases nobres.

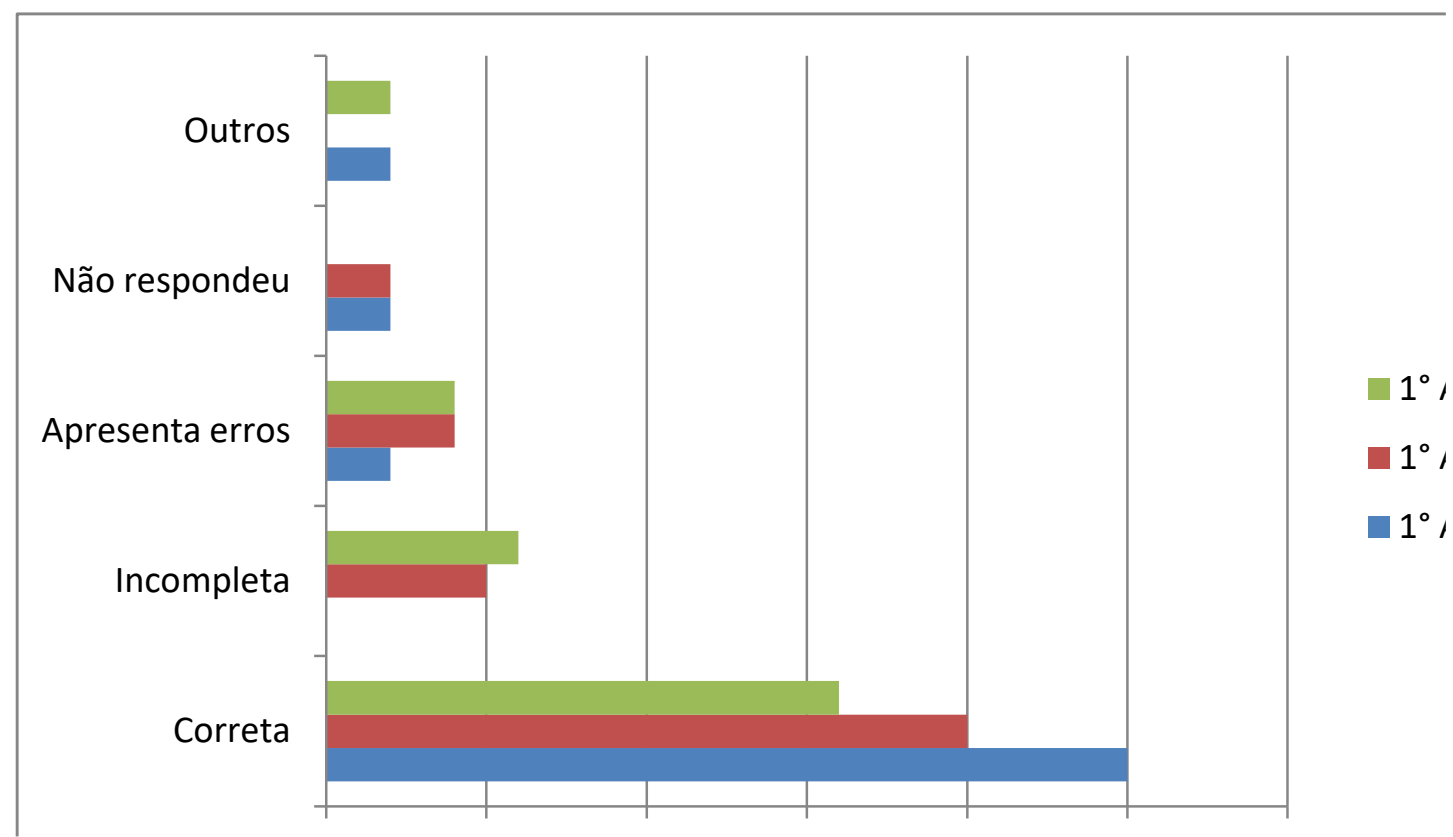

Fonte: Autores (2021).

Algumas das respostas apresentadas pelos alunos:

Aluno 1: METAIS: Cálcio e Potássio;

AMETAIS: Hidrogênio, nitrogênio, oxigênio, carbono e fósforo.

O aluno 1 apresentou uma resposta que é considerada correta, visto que o potássio é um metal alcalino, o cálcio é um metal alcalino terroso e os demais elementos são classificados como não metais ou ametais (ATKINS; JONES, 2006).

Aluno 2: METAIS: Cálcio;

AMETAIS: Fósforo e potássio;

GASES NOBRES: Oxigênio, carbono, hidrogênio e nitrogênio.

Aluno 3: REPRESENTATIVOS: Hidrogênio e potássio;

AMETAIS: nitrogênio, oxigênio, carbono, fósforo;

METAIS DE TRANSAÇÃO EXTERNA: Cálcio.

As respostas dos aluno 2 e 3 apresentam confusão com relação aos estados dos elementos e com a classificação dos mesmo frente a tabela periódica.

Aluno 4: METAIS: Possuem brilho, são sólidos, cátions, bons condutores de calor e energia;

AMETAIS: Ânions, não são bons condutores de calor e energia;

GASES NOBRES: Não são muito reativos, isolado.

A resposta feita pelo aluno 4 está incorreta com relação a perguntas feita, e se encaixa na categoria outro, visto que a resposta não está relacionada com a pergunta, entretanto vale ressaltar que ela está correta com relação há características que tais elementos apresentam.

A segunda questão utilizada para a organização do conhecimento: Localize-os dentro da tabela periódica sua família e período. Ainda se referindo aos elementos trabalhados na questão 1. A Figura 6 apresenta as respostas dos alunos classificados de acordo com as categorias descritas anteriormente. 
Figura 6. Respostas referentes à questão 2 - Localize-os dentro da tabela periódica sua família e período.

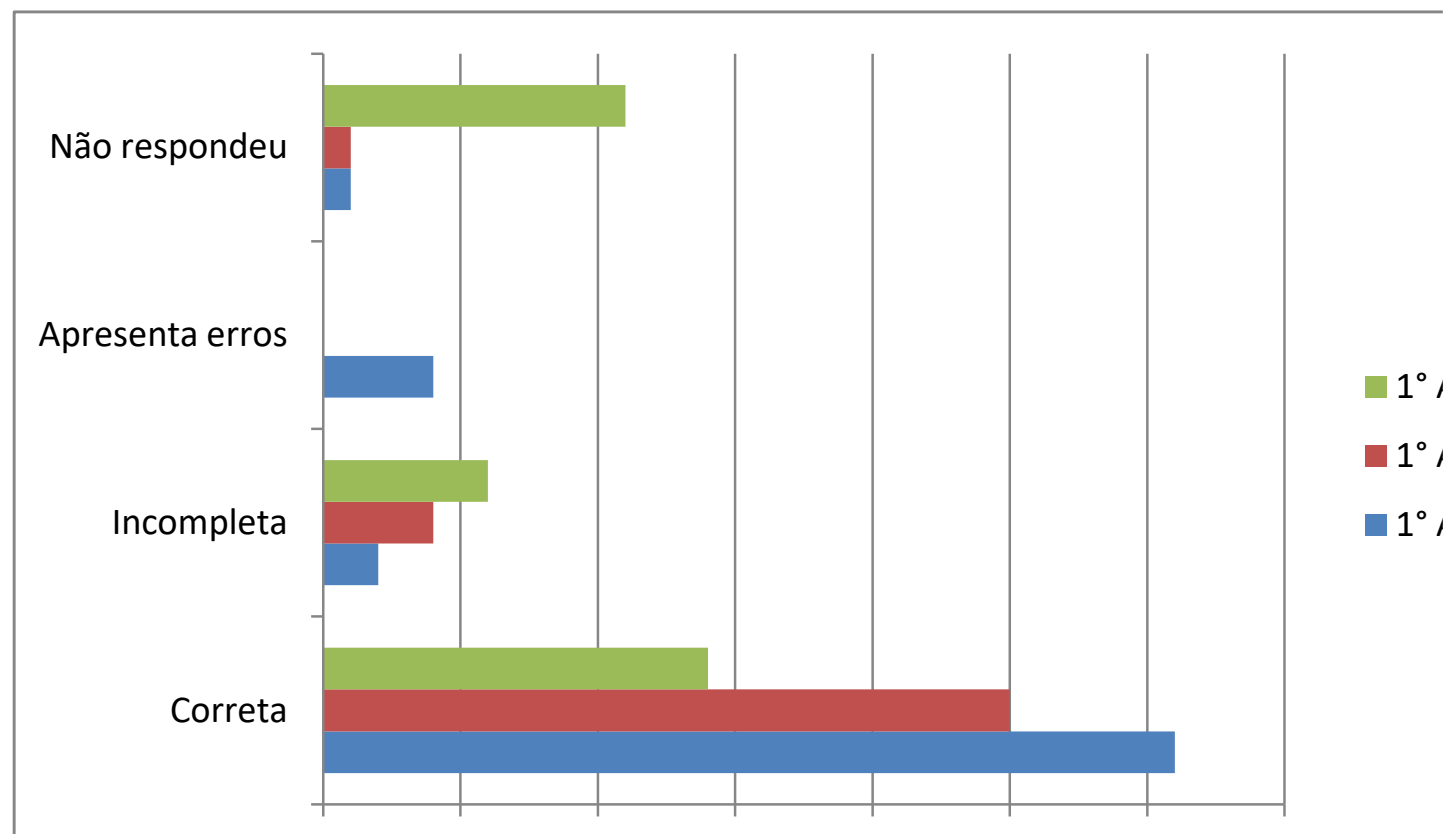

Fonte: Autores (2021).

A questão dois apresentou maior número de acertos, visto que a maioria dos estudantes conseguiu assimilar como classificar o elemento em período e família correspondente.

A extrapolação do conteúdo se deu início no final da terceira aula sequência com um jogo e segundo as Orientações Curriculares para o Ensino Médio (Brasil, 2006) oferece o estímulo e o ambiente propícios que favorecem o desenvolvimento espontâneo e criativo dos alunos permitindo ao professor ampliar seu conhecimento de técnicas ativas de ensino. De tal forma, o jogo possibilita o desenvolvimento da aprendizagem dos alunos e também permite que tanto o professor quanto o aluno repensem sobre suas ações concernentes a construção da aprendizagem significativa, onde o jogo, neste contexto, além de ser uma ferramenta preponderante para a construção do saber pode ser utilizada como metodologia avaliativa no processo de ensino e aprendizagem.

A avaliação da aprendizagem, não é apenas pontuar o coeficiente do aluno em determinado assunto ou disciplina, segundo Hoffmann (2003) a avaliação deixa de ser um momento terminal do processo educativo para se transformar na busca incessante de compreensão das dificuldades do educando e na dinamização de novas oportunidades de conhecimento. Assim, o jogo como ferramenta avaliativa repercute na integração de forma lúdica o desenvolvimento e o desempenho do aluno acerca dos conteúdos de Química no Ensino Médio.

O jogo utilizado foi o XeNUBi, desenvolvido por pesquisadores da UFSC e UFRGS (Eichler, Perry, Panichi, \& Fritsch, 2013), em que o jogo possui como base as propriedades periódicas dos elementos, algo trabalhado na sequência, e o jogo buscavam fazer os alunos utilizarem os conhecimentos adquiridos durante a sequência para vencer os adversários.

O jogo favorece a aquisição de conhecimento de maneira descontraída, fugindo do ensino tradicional e como os jogos didáticos apresentam aspectos lúdicos e cognitivos se mostram vantajosos para o ensino, pois favorecem a motivação, o raciocínio, a argumentação e a interação entre os alunos e com o professor (Zanon, Guerreiro, \& Oliveira, 2008).

A Figura 7 mostra algumas das 96 cartas contidas no baralho do jogo e as propriedades trazidas pelo jogo, sendo elas o raio atômico, energia de ionização, eletroafinidade, eletronegatividade, ponto de fusão e densidade. 
Figura 7. Cartas do jogo XeNUBi.

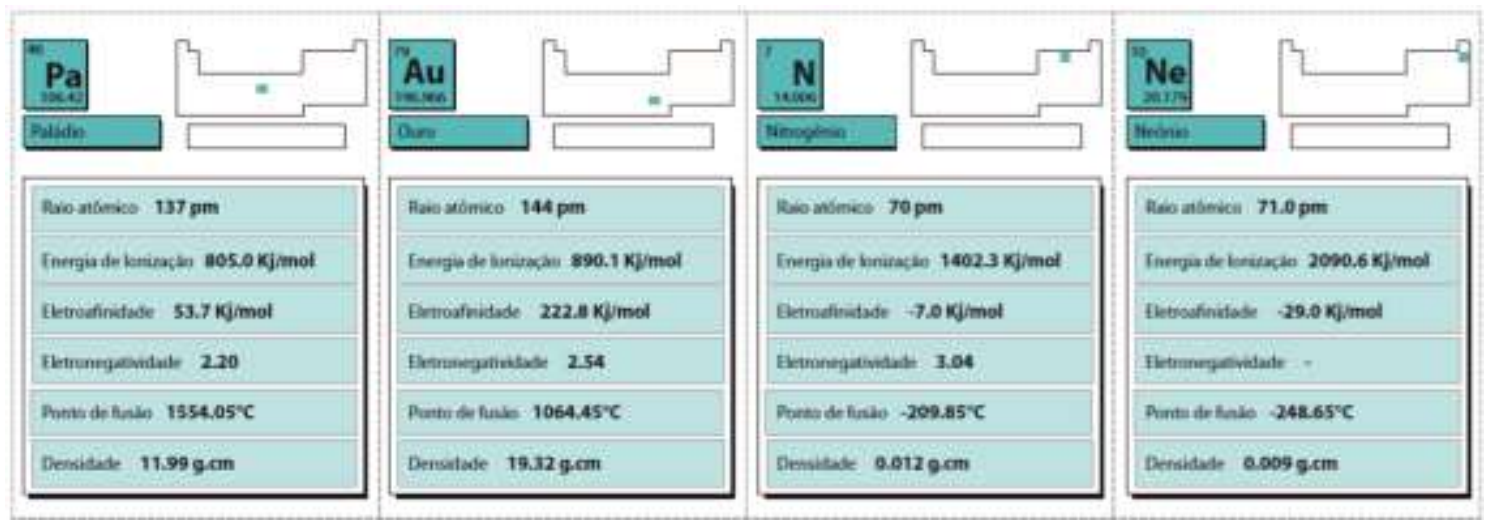

Fonte: Eichler, Perry, Panichi, \& Fritsch (2013).

Foi possível observar que durante o jogo os estudantes buscaram a melhor propriedade para vencer o adversário, utilizando da tabela periódica e do caderno para determinar qual seria a escolha correta em relação ao elemento que o jogador adversário possuía.

A última atividade proposta para os alunos foi feita de maneira individual e buscava comprovar se os estudantes haviam adquirido conhecimento por meio da sequência. Como a sequência trabalhava os elementos contidos no corpo humano, utilizar de alimentos que os humanos consomem que contém elementos químicos, se mostra vantajoso para observar se os alunos conseguem relacionar o que foi aprendido em sala com seu cotidiano.

Foram entregues rótulos de alimentos para que os alunos identificassem os elementos contidos nos alimentos e classificassem em ordem crescente de raio atômico e posteriormente apresentassem a classificação os elementos na tabela periódica.

A Figura 8 utiliza das categorias criadas na organização do conhecimento para classificar as respostas referentes a extrapolação realizada ao final da sequência. 
Figura 8. Respostas referentes à extrapolação do conteúdo.

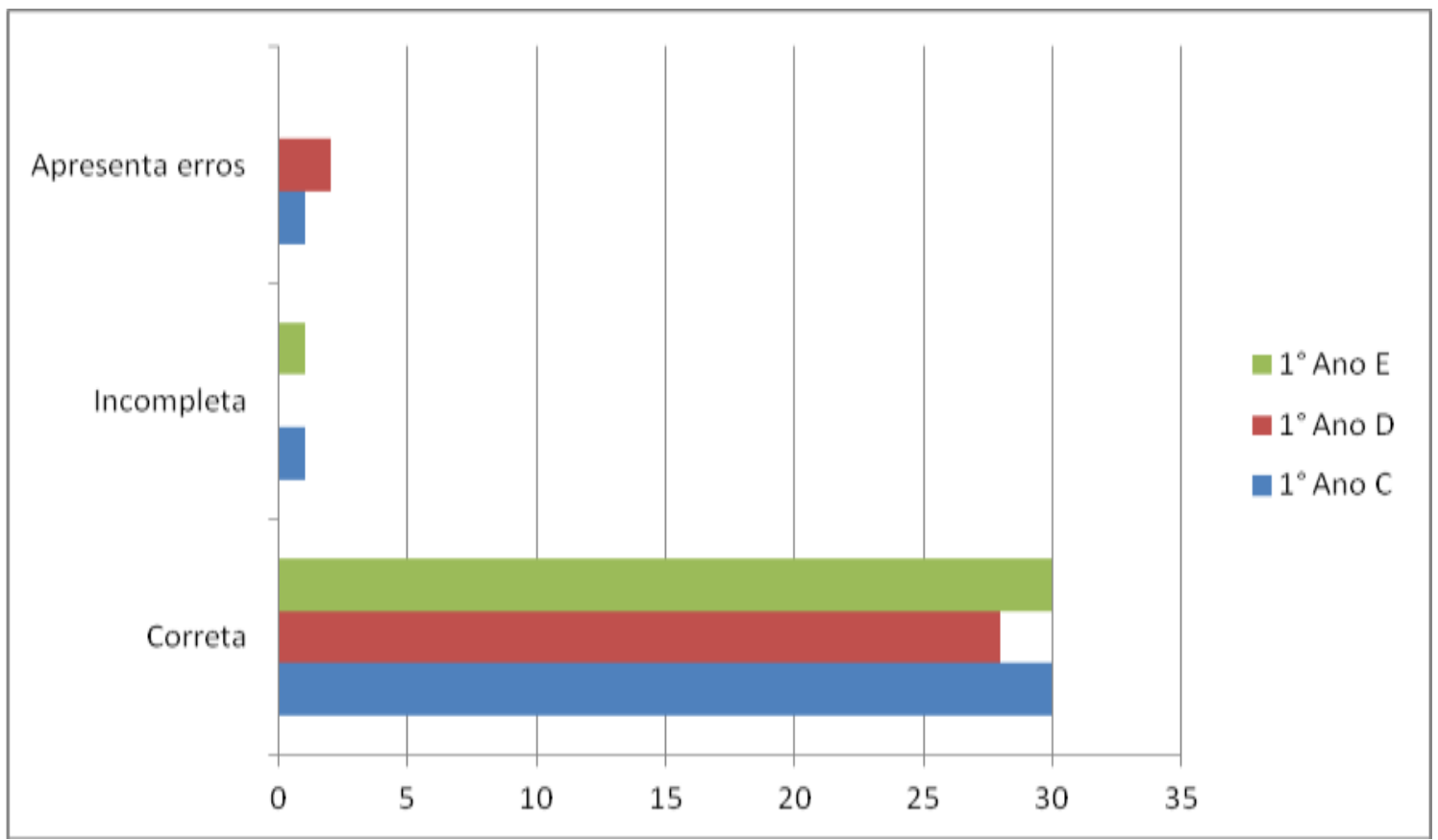

Fonte: Autores (2021).

A grande a maioria dos alunos acertou as questões e isso mostra que a sequência foi eficaz no quesito de associar o que foi visto em sala com o dia a dia. Poucos alunos não devolveram a folha de resposta.

\section{Considerações Finais}

Portanto a partir da elaboração e aplicação da sequência didática ficou evidenciado que despertou o interesse dos estudantes. Que a contextualização é algo muito importante pois quando utilizamos da mesma a química deixa de ser uma ciência tão abstrata e tão difícil, pois os estudantes percebem que ela está inserida no seu cotidiano.

Também é possível concluir que a presente sequência favoreceu a aprendizagem de conceitos sobre a tabela periódica, e que essa ferramenta de ensino favorece o debate dentro da sala de aula, traz o aluno para uma forma mais ativa do seu processo de ensino e aprendizagem, e o estudante a partir das discussões torna um cidadão mais atuante na sociedade.

$\mathrm{O}$ uso de metodologias ativas deve ser encorajado, dessa forma, trabalhos futuros que utilizem metodologias ativas como os três momentos pedagógicos, ou experimentação no ensino de química se fazem extremamente importantes.

\section{Agradecimentos}

Os autores agradecem ao Conselho Nacional de Desenvolvimento Científico e Tecnológico (CNPq) e Coordenação de Aperfeiçoamento de Pessoal de Nível Superior (CAPES) pelo auxílio financeiro.

\section{Referências}

Atkins, P., Jones, L., \& Laverman, L. (2018). Princípios de Química-: Questionando a Vida Moderna e o Meio Ambiente. Bookman Editora.

Brasil (1999). Parâmetros Curriculares Nacionais do Ensino Médio. Brasília: MEC; SEMTEC.

Brasil (2006) Ministério da Educação. Secretaria de Educação Básica. Orientações Curriculares para o Ensino Médio: Ciências da natureza, Matemática e suas Tecnologias. Brasília:MEC/SEB. 
Research, Society and Development, v. 10, n. 13, e574101321591, 2021

(CC BY 4.0) | ISSN 2525-3409 | DOI: http://dx.doi.org/10.33448/rsd-v10i13.21591

Almeida, E. C. S., da Silva, M. D. F. C., de Lima, J. P., da Silva, M. L., Braga, C. D. F., \& Brasilino, M. D. G. A. (2008). Contextualização do ensino de química: motivando alunos de ensino médio. XVI Encontro Nacional de Ensino de Química (XVI ENEQ) e X Encontro de Educação Química da Bahia (X EDUQUI), Salvador, BA, Brasil-17, 20.

Delizoicov, D. (2001). Problemas e problematizações. Ensino de Física: conteúdo, metodologia e epistemologia numa concepção integradora. Florianópolis: Ed. da UFSC, 125-150.

Eichler, M. L., Perry, G. T., Panichi, M., \& Fritsch, G. O. (2013). Xenubi-jogo sobre propriedades periódicas

Godoy, C., \& Mesquita, N. A. (2012). Identificando relações de ensino aprendizagem do livro didático ao vestibular: as Propriedades Periódicas como foco investigativo. XVI ENEQ/X EDUQUI-ISSN: 2179-5355.

Help Química (2021). Aula 24 - Documentário - História da tabela periódica. https://www.youtube.com/watch?v=8QNLfwjbzZw

Hoffmann, J. (2003). Avaliação: mito e desafio: uma perspectiva construtivista.

Levorato, A., Auwerter, A., Nery, B., Cebulski, E., Politano, J., Buzatto, M., ... \& Stadler, Z. (2006). Química-Ensino Médio. Curitiba: SEED-PR, 248.

Lyra, D. G. G. (2013). Os três momentos pedagógicos no ensino de ciências na educação de jovens e adultos da rede pública de Goiânia, Goiás: o caso da dengue.

Marengão, L. S. L. (2012). Os Três Momentos Pedagógicos e a elaboração de problemas de Física pelos estudantes.

Medeiros, M. D. A. (2013). Avaliação do conhecimento sobre periodicidade química em uma turma de química geral do ensino a distância. Química Nova, 36, 474-479.

Nunes, P. P. (2017). Contextualização e abordagem de conceitos químicos por meio da química forense: uma sequência didática para o Ensino Médio no Ensino da Química.

Pereira, A. S., Shitsuka, D. M., Pereira, F. J., \& Shitsuka, R. (2018). Metodologia da pesquisa científica. [eBook]. Santa Maria. Ed. UAB / NTE

/ UFSM. https://repositorio.ufsm.br/bitstream/handle/1/15824/Lic_Computacao_Metodologia-Pesquisa-Cientifica.pdf?sequence=1.

Silva, A. M. (2011). Proposta para tornar o ensino de química mais atraente. Revista Química Industrial, 711.

Silva, C. S., \& Oliveira, L. A. A. (2009). Formação inicial de professores de química: formação específica e pedagógica. Ensino de Ciências e Matemática I: temas sobre a formação de professores. São Paulo: Cultura Acadêmica, 43-58.

Silva, F. M., \& Coffani, M. C. R. da S. (2013). OO lugar da educação física no ensino médio: entre a presença e ausência do aluno. Conexões, 11, 159-178.

Trassi, R. C. M., Castellani, A. M., Gonçalves, J. E., \& Toledo, E. A. (2001). Tabela periódica interativa: "um estímulo à compreensão". Acta Scientiarum. Technology, 23, 1335-1339.

Wartha, E. J., Silva, E. D., \& Bejarano, N. R. R. (2013). Cotidiano e contextualização no ensino de química. Química nova na escola, 35, 84-91.

Zanon, D. A. V., Guerreiro, M. A. da S., \& Oliveira, R. C. (2008). Jogo didático Ludo Químico para o ensino de nomenclatura dos compostos orgânicos: projeto, produção, aplicação e avaliação. Ciências \& Cognição, 13. 